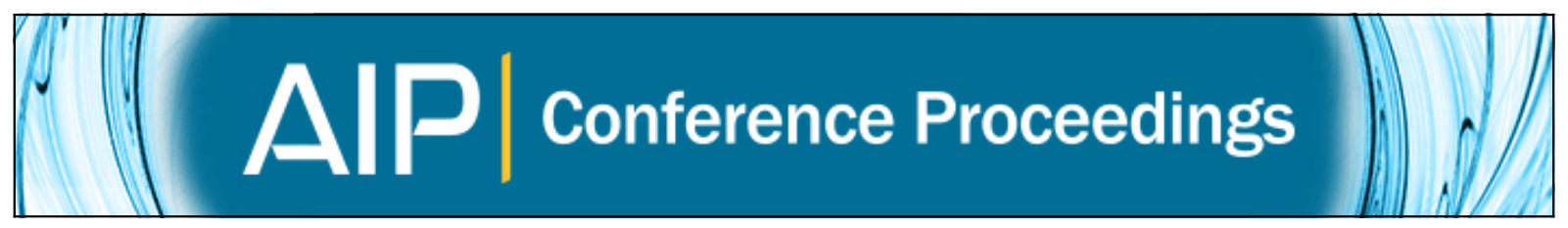

Experimental study on the influence of dimethylamine on the detection of gas phase sulfuric acid using chemical ionization mass spectrometry (CIMS)

L. Rondo, M. Leiminger, M. Simon, S. Ehrhart, C. Williamson, A. Praplan, A. Kürten, J. Kirkby, J. Curtius, and CLOUD Collaboration

Citation: AIP Conference Proceedings 1527, 374 (2013); doi: 10.1063/1.4803281

View online: http://dx.doi.org/10.1063/1.4803281

View Table of Contents: http://scitation.aip.org/content/aip/proceeding/aipcp/1527?ver=pdfcov

Published by the AIP Publishing

Articles you may be interested in

Measurement of neutral sulfuric acid-dimethylamine clusters using Cl-APi-TOF-MS

AIP Conf. Proc. 1527, 377 (2013); 10.1063/1.4803282

Laser resonance ionization mass spectrometry for failed fuel detection and location in the experimental fast reactor JOYO

AIP Conf. Proc. 584, 125 (2001); 10.1063/1.1405592

Study of laser resonance ionization mass spectrometry using a glow discharge source

AIP Conf. Proc. 329, 316 (1995); 10.1063/1.47573

Chemical precursor to optical damage detected by laser ionization mass spectrometry

Appl. Phys. Lett. 52, 2205 (1988); 10.1063/1.99766

Gas Analysis by Photo-lonization Mass Spectrometry

J. Appl. Phys. 37, 2812 (1966); 10.1063/1.1782129 


\title{
Experimental study on the influence of dimethylamine on the detection of gas phase sulfuric acid using Chemical Ionization Mass Spectrometry (CIMS)
}

\author{
L. Rondo ${ }^{\mathrm{a}}$, M. Leiminger ${ }^{\mathrm{a}}$, M. Simon ${ }^{\mathrm{a}}, \mathrm{S}$. Ehrhart ${ }^{\mathrm{a}}$, C. Williamson ${ }^{\mathrm{a}}$, \\ A. Praplan ${ }^{\text {b,c }}$, A. Kürten ${ }^{\mathrm{a}}$, J. Kirkby ${ }^{\mathrm{d}}$, J. Curtius ${ }^{\mathrm{a}}$, \\ and the CLOUD collaboration \\ ${ }^{a}$ Institute for Atmospheric and Environmental Sciences, Goethe University of Frankfurt, Germany \\ ${ }^{b}$ Laboratory of Atmospheric Chemistry, Paul Scherrer Institute, Villigen, Switzerland \\ ${ }^{c}$ Department of Physics, University of Helsinki, University of Helsinki, Finland \\ ${ }^{d}$ CERN, Geneva, Switzerland
}

\begin{abstract}
Based on quantum chemistry calculations it has been suggested that the quantitative detection of gas phase sulfuric acid $\left(\mathrm{H}_{2} \mathrm{SO}_{4}\right)$ by use of Chemical Ionization Mass Spectrometry (CIMS) could be biased in the presence of gas phase amines such as dimethylamine (DMA). An experiment was set up at the CLOUD aerosol chamber to test the quantitative detection of $\mathrm{H}_{2} \mathrm{SO}_{4}$ by CIMS by directly comparing the measured $\mathrm{H}_{2} \mathrm{SO}_{4}$ with and without DMA being present in the sample air. It was found that the $\mathrm{H}_{2} \mathrm{SO}_{4}$ cluster distribution changes but the CIMS detection efficiency is not strongly influenced.
\end{abstract}

Keywords: Chamber study, CLOUD experiment, sulfuric acid, new particle formation.

PACS: $82.60 . \mathrm{Nh}$

\section{INTRODUCTION}

The nucleation of particles in the atmosphere is an important source for the atmospheric particle population and model calculations suggest that it could be responsible for about half of the global cloud condensation nuclei ${ }^{1}$. Sulfuric acid $\left(\mathrm{H}_{2} \mathrm{SO}_{4}\right)$ is widely recognized as the most important substance driving atmospheric aerosol nucleation ${ }^{2}$. The method commonly used to detect gas phase $\mathrm{H}_{2} \mathrm{SO}_{4}$ is Chemical Ionization Mass Spectrometry (CIMS) which allows very sensitive detection of $\mathrm{H}_{2} \mathrm{SO}_{4}$ down to levels below $1 \times 10^{5}$ molecule per cubic centimeter, ${ }^{3,4}$. For detection with a mass spectrometer, $\mathrm{H}_{2} \mathrm{SO}_{4}$ is converted into bisulfate ions $\left(\mathrm{HSO}_{4}{ }^{-}\right)$by reaction with nitrate ions $\left(\mathrm{NO}^{-}\right)$which can be clustered with nitric acid $\left(\mathrm{HNO}_{3}\right)$ or water molecules. Viggiano et al. showed that these reactions proceed with reaction rates close to the collision limit ${ }^{5}$. Recently, Kurtén et al. raised the question in how far this detection scheme is still valid if amines are present in the sample air ${ }^{6}$. Potentially the reaction with $\mathrm{NO}_{3}{ }^{-}$could be considerably less efficient if the $\mathrm{H}_{2} \mathrm{SO}_{4}$ molecules are each clustered with one or two dimethylamine (DMA) molecules. As these clustered $\mathrm{H}_{2} \mathrm{SO}_{4}$ molecules will continue to participate in the nucleation and growth - most

Nucleation and Atmospheric Aerosols

AIP Conf. Proc. 1527, 374-376 (2013); doi: 10.1063/1.4803281

(C) 2013 AIP Publishing LLC 978-0-7354-1152-4/\$30.00 
likely even more efficiently than the bare molecules - it is desired to measure the gas phase concentration of $\mathrm{H}_{2} \mathrm{SO}_{4}$ molecules regardless of whether they occur as the bare $\mathrm{H}_{2} \mathrm{SO}_{4}$ molecule or clustered with amines (or other molecules such as water or ammonia). The detection of gas phase $\mathrm{H}_{2} \mathrm{SO}_{4}$ could be interpreted to yield much lower $\mathrm{H}_{2} \mathrm{SO}_{4}$ concentration if the detection scheme was less efficient in the presence of amines. Although this effect was predicted to be only on the order of ten percent by the most reliable quantum chemistry computations ${ }^{6}$ it was decided to investigate this potential influence by a dedicated experimental study at the CLOUD aerosol chamber at CERN.

\section{EXPERIMENTAL METHODS}

The CLOUD aerosol chamber ${ }^{7}$ allows the stable in situ production of gaseous $\mathrm{H}_{2} \mathrm{SO}_{4}$ from the $\mathrm{SO}_{2}+\mathrm{OH}$ reaction ${ }^{8}$. The $\mathrm{H}_{2} \mathrm{SO}_{4}$ concentration is monitored by a wellcalibrated CIMS instrument ${ }^{3}$ (THS Instruments) as well as CI-APiTOF mass spectrometry $^{4}$ (Tofwerk AG/Aerodyne Research, Inc.). It is an important advantage of the CLOUD aerosol chamber that contamination by amines, or other condensable organic or inorganic species are kept to extremely low levels (few pptv level or below) and a large number of these species is constantly monitored. Furthermore, loss of $\mathrm{H}_{2} \mathrm{SO}_{4}$ due to nucleation, wall losses and gas dilution in the chamber is monitored as well by various instruments and other potentially influencing factors such as relative humidity, gas temperature and pressure are also kept precisely constant ${ }^{7}$. This allows conducting nucleation experiments and other process studies at atmosphericallyrelevant levels.

We performed a series of measurements by creating a range of different $\mathrm{H}_{2} \mathrm{SO}_{4}$ concentrations $\left(\mathrm{H}_{2} \mathrm{SO}_{4}\right.$ ranging from $1 \times 10^{6}$ to $\left.1 \times 10^{8} \mathrm{~cm}^{-3}\right)$ in the CLOUD chamber, first without any measurable amounts of DMA present in the chamber $(<0.2 \mathrm{pptv})$, and then repeating the exact same measurements while introducing DMA at levels of 10 and 40 pptv into the chamber. DMA levels are monitored by use of ion chromatography 9 .

\section{RESULTS}

While the additional DMA substantially influences the observed cluster distribution, the detailed analysis shows that the detection efficiency of the CIMS is not affected strongly by the presence of DMA. Results will be quantified and discussed at the conference.

\section{ACKNOWLEDGMENTS}

We would like to thank CERN for supporting CLOUD with important technical and financial resources, and for providing a particle beam from the CERN Proton Synchrotron. This research has received funding from the EC Seventh Framework Programme (Marie Curie Initial Training Network "CLOUD-ITN" no. 215072, MCITN "CLOUD-TRAIN", no. 316662, and ERC-Advanced "ATMNUCLE" grant no. 
227463), the German Federal Ministry of Education and Research (project nos. 01LK0902A and 01LK1222A), the Swiss National Science Foundation (project nos. 200020_135307 and 206620_130527), the Academy of Finland Center of Excellence program (project no. 1118615), the Academy of Finland (CoE project no. 1118615, LASTU project no. 135054), the Nessling Foundation, the Austrian Science Fund (FWF; project no. P19546 and L593), the Portuguese Foundation for Science and Technology (project no. CERN/FP/116387/2010), the Swedish Research Council, Vetenskapsrådet (grant 2011-5120), the Presidium of the Russian Academy of Sciences and Russian Foundation for Basic Research (grants 08-02-91006-CERN and 12-02-91522-CERN), and the U.S. National Science Foundation (grants AGS1136479 and CHE1012293).

\section{REFERENCES}

1. J. Merikanto et al., Atmos. Chem. Phys. 9, 8601-8616 (2009).

2. S.-L. Sihto et al., Atmos. Chem. Phys. 6, 4079-4091 (2006).

3. A. Kürten et al., J. Phys. Chem. A 116, 6375-6386 (2012).

4. T. Jokinen et al., Atmos. Chem. Phys. 12, 4117-4125 (2012).

5. A. A. Viggiano et al., J. Chem. Phys. A 101, 8275-8278 (1997).

6. T. Kurtén et al., Atmos. Chem. Phys. 11, 3007-3019, (2011).

7. J. Kirkby et al., Nature 476, 429-433 (2011).

8. A. Kupc et al., J. Aerosol Sci. 42, 8, 535-543, (2011).

9. A. P. Praplan et al., Atmos. Meas. Tech. 5, 2161-2167 (2012). 